\title{
Relationship Between Grip and Pinch Strength and Activities of Daily Living in Stroke Patients
}

\author{
Jung Hyun Bae, MD, Si Hyun Kang, MD, PhD, Kyung Mook Seo, MD, PhD, \\ Don-Kyu Kim, MD, PhD, Hyun Iee Shin, MD, Hye Eun Shin, MD
}

Departments of Physical Medicine and Rehabilitation, Chung-Ang University College of Medicine, Seoul, Korea

Objective To investigate the relationship between grip and pinch strength and independence in activities of daily living (ADL) in stroke patients.

Methods Medical records of 577 stroke patients from January 2010 to February 2013 were retrospectively reviewed. Patients' grip and pinch strength of both hemiplegic and non-hemiplegic hands and the Korean version of Modified Barthel Index (K-MBI) score were collected. These patients were divided into three groups: group A (onset duration: $\leq 3$ months), group B (onset duration: $>3$ months and $<2$ years), and group C (onset duration: $\geq 2$ years). The correlation between grip and pinch strength and the K-MBI score was analyzed.

Results In group A (95 patients), the K-MBI score was significantly $(\mathrm{p}<0.05)$ correlated with the grip and pinch strength of both hands in patients with right hemiplegia. Significant $(\mathrm{p}<0.05)$ correlation between the K-MBI score and the grip and pinch strength of the hemiplegic hand was shown in patients with left hemiplegia. In group B (69 patients) and group C (73 patients), the K-MBI score was significantly $(\mathrm{p}<0.05)$ correlated with the grip and pinch strength of the hemiplegic hand.

Conclusion Stroke patients in subacute stage mainly performed activities of daily living using their dominant hand. However, independence in ADL was associated with the strength of the affected dominant hand. For stroke patients in chronic and late chronic stages, their hand power of the affected hand was associated with independence in ADL regardless whether the dominant hand was affected.

Keywords Activities of daily living, Functional laterality, Hand strength, Pinch strength, Stroke

Received February 10, 2015; Accepted April 16, 2015

Corresponding author: Si Hyun Kang

Department of Physical Medicine and Rehabilitation, Chung-Ang University College of Medicine, 102 Heukseok-ro, Dongjak-gu, Seoul 06973, Korea

Tel: +82-2-6299-1883, Fax: +82-2-6298-1866, E-mail: sihyun92@cau.ac.kr

(c) This is an open-access article distributed under the terms of the Creative Commons Attribution Non-Commercial License (http://creativecommons. org/licenses/by-nc/4.0) which permits unrestricted noncommercial use, distribution, and reproduction in any medium, provided the original work is properly cited.

Copyright $\odot 2015$ by Korean Academy of Rehabilitation Medicine

\section{INTRODUCTION}

The most recent treatment strategy for stroke patients is based on the neurophysiologic mechanism including brain plasticity for post-stroke recovery $[1,2]$. Accordingly, rehabilitation specialists can have two options. The first is a restorative approach to recover the affected hand functions. The second option is a compensatory approach to replace the functions of affected hand. Select- 
ing which option is still on debate [3].

The 'constraint-induced therapy' of unaffected side upper extremities is a representatively suggested method of the restorative approach whose effects have been well recognized [4,5]. Nevertheless, this method can be used only for patients who still have some muscle strengths in their affected upper extremities, thus limiting indicated patient groups. Necessity of bilateral training for not only the affected upper extremities but also the unaffected side has been suggested [1]. What is important in selecting these treatment methods is the possible difference between the dominant hand and the nondominant hand [6]. In many stroke patients with affected nondominant hemisphere, their nondominant hand is paralyzed. However, their dominant hand can be used for activities of daily living (ADL) and their will for treating their nondominant hand is often weaker than patients whose dominant hand is paralyzed. For patients whose dominant hand is paralyzed, treatments for nondominant hand for minute ADL such as hand writing and using chopsticks are always insufficient. Accordingly, they are usually highly motivated to have dominant hand rehabilitation such as unaffected-side upper extremities constraint-induced therapy regardless of their paralysis level. Such motivation often continues up to the chronic stage. The preference to the dominant hand rather than to the nondominant hand has been reported in previous studies [7]. The differences in needs for hand rehabilitation between dominant hand and nondominant hand in hemiplegic stroke patients will afftect the selection of treatment approach. Various methods of hand rehabilitation have been suggested for patients with paralyzed dominant hand.

The goal of rehabilitation is to enhance ADL performance so that patients can eventually carry out ADL independently. Various tools have been used for evaluating the status of stroke patients and the achievement of treatment goals. Barthel Index (BI) and Functional Independence Measure (FIM) are representative assessment tools for ADL. BI was revised as Modified Barthel Index (MBI) to be more conveniently and effectively used all over the world $[8,9]$. In Korea, the Korean version of Modified Barthel Index (K-MBI) has been developed [10]. Various tools for assessing the upper extremities that play important roles in ADL have also been developed. Loss of upper extremity functions is determined based on the levels of paresis, loss of fractionated movements, abnormal muscle tone, and somatosensation impairments. The level of paresis contributes to the upper extremity function loss by $88 \% 3$ weeks after stroke, and $73 \% 6$ months after stroke. The grip strength and pinch strength are useful for determining the paralysis level $[3,11]$. Their reliability and validity as indicators have been verified in previous studies [12-14]. The association of the functional assessment or self-reporting questionnaire with ADL performance and the usefulness of the grip and pinch strengths for making early prognoses have been verified $[15,16]$. However, few objective studies on the association of the grip or pinch strength with ADL performance after stroke based on stage have been conducted.

In this study, the correlation between the grip and pinch strengths of the paralyzed hand and ADL performance was investigated. The grip strength that could be easily measured and quantitized compared to other complex assessment methods and the tendency of the pinch strength during the subacute to the late chronic stages were investigated to compare them with the ADL performances. As a result, objective data of hand rehabilitation treatments in stroke patients were obtained.

\section{MATERIALS AND METHODS}

\section{Subjects}

Medical records of 577 hemiplegic patients who were admitted or visited the rehabilitation department of Chung-ang University Hospital between January 1, 2010 and December 31, 2013 were reviewed. The exclusion criteria were as follows: recurrent stroke; quadriplegia or double hemiplegia; accompaniment of neurologic diseases such as the Parkinson disease; and right dominant hemisphere (left dominant hand). To exclude the effects of cognitive functions that could affect measurement results, ischemic and hemorrhagic stroke patients who had 20 or higher score of Korean version of Mini Mental Status Examination (MMSE-K) and those could do two-step obey command were selected for this study.

\section{Data collection}

Demographic data such as age, gender, ADL performance, and grip and pinch strengths were collected. The subjects were assigned to subacute stage (within 3 months), chronic stage (3 months to 2 years), and late 
chronic stage (more than 2 years) groups which were named as group A, group B, and group $\mathrm{C}$, respectively [17]. Four occupational therapists collected ADL performance data using K-MBI. The total score of 10 items and the total scores of 5 items that reflected hand functions for hygiene, bathing, feeding, toileting, and dressing were collected separately. On the day of assessing ADL performance, grip strength and three pinch strengths including lateral pinch (key pinch) strength, palmar pinch (threejaw chuck pinch) strength, and tip pinch (two-point pinch) strength were measured using an electronic grip and pinch strengths measurer [18]. For measurements of the grip and pinch strengths, E-LINK Hand Kit H400 including G100 dynamometer and P100 pinchmeter (Biometrics Ltd., Gwent, UK) was used. This retrospective study was based on the medical records of patients who were admitted to Chung-Ang University Hospital. An approval from Institutional Review Board was obtained prior to collecting data.

\section{Statistical analyses}

Windows PASW 17.0 (SPSS Inc., Chicago, IL, USA) was used for statistical analyses. Student t-test and chi-square test were used for determining the difference in age, MMSE-K score, gender distribution, and stroke type by stage. Pearson correlation coefficient ( $\mathrm{r}$ ) was calculated to determine the relationship between the grip and pinch strength and the K-MBI score.

\section{RESULTS}

\section{Demographic data and their distribution (Table 1)}

The 237 subjects (136 females, 101 males) had a mean age of $60.84 \pm 13.70$ years (range, 19 to 84 years). They were assigned to group A ( $n=95)$, group $B(n=69)$, or group C $(\mathrm{n}=73)$. Of the 237 subjects, $133(56.1 \%)$ and $104(43.9 \%)$ were right hemiplegic and left hemiplegic, respectively. Based on the type of stroke, there were 127 (53.6\%) hemorrhagic stroke and 110 (46.4\%) ischemic stroke. The mean MMSE-K score and K-MBI score of all subjects were $25.72 \pm 3.19$ and $72.78 \pm 20.86$, respectively.

In group $\mathrm{A}$, the number of right and left hemiplegic patients was $55(57.9 \%)$ and $40(42.1 \%)$, respectively. There were $57(60 \%)$ males and $38(40 \%)$ females. Their mean age was $62.75 \pm 12.51$ years. Based on the type of stroke, there were 43 (45.3\%) hemorrhagic stroke subjects and 52 (54.7\%) ischemic stroke subjects. Their mean MMSE-K score and K-MBI scores were 25.46 \pm 3.05 and $68.35 \pm 22.65$, respectively.

In group $B$, the number of right hemiplegic patients was $43(62.3 \%)$ and the number of left hemiplegic patients was 26 (37.7\%). There were 38 (55.1\%) males and 31 (44.9\%) females. Their mean age was $57.93 \pm 16.73$ years. Based on the type of stroke, the number of hemorrhagic stroke patient was $40(58.0 \%)$ and the number of ischemic stroke was 29 (42.0\%). Their mean MMSE-K score and KMBI score were $25.64 \pm 3.37$ and $72.78 \pm 19.73$, respectively.

In group $\mathrm{C}$, the number of right and left hemiplegic patients was 35 (47.9\%) and $38(52.1 \%)$, respectively. There

Table 1. Demographics, characteristics, and K-MBI of patients

\begin{tabular}{|lccc}
\hline & Group A & Group B & Group C \\
\hline Sex (male:female) & $57: 38$ & $38: 31$ & $41: 32$ \\
\hline Age (yr) & $62.75 \pm 12.51$ & $57.93 \pm 16.73$ & $61.12 \pm 11.54$ \\
\hline Etiology (hemorrhagic:ischemic) & $43: 52$ & $40: 29$ & $44: 29$ \\
\hline MMSE-K & $25.46 \pm 3.05$ & $25.64 \pm 3.37$ & $26.12 \pm 3.22$ \\
\hline Examination day from onset & $41.82 \pm 22.92$ & $276.19 \pm 145.67$ & $1,791.41 \pm 1,219.54$ \\
\hline K-MBI & $68.35 \pm 22.65$ & $72.78 \pm 19.73$ & $78.55 \pm 18.16$ \\
\hline Hygiene & $3.29 \pm 1.21$ & $3.30 \pm 1.03$ & $3.77 \pm 0.79$ \\
\hline Bathing & $2.72 \pm 1.40$ & $2.68 \pm 1.38$ & $3.10 \pm 1.17$ \\
\hline Feeding & $7.23 \pm 2.46$ & $7.77 \pm 1.89$ & $8.04 \pm 1.54$ \\
\hline Toileting & $6.42 \pm 2.96$ & $6.58 \pm 2.67$ & $7.33 \pm 2.32$ \\
\hline Dressing & $5.99 \pm 2.78$ & $6.29 \pm 2.54$ & $7.34 \pm 2.17$ \\
\hline
\end{tabular}

Values are presented as mean \pm standard deviation.

K-MBI, Korean version of Modified Barthel Index; MMSE-K, Korean version of Mini Mental Status Examination. 
were $41(56.2 \%)$ males and $32(43.8 \%)$ females. Their mean age was $61.12 \pm 11.54$ years. Based on the type of stroke, the number of hemorrhagic stroke and ischemic strok patients was 44 (60.3\%) and 29 (39.7\%), respectively. Their mean MMSE-K score was $26.12 \pm 3.22$. The mean KMBI score was $78.55 \pm 18.16$. There was no significant difference in age, gender distribution, or stroke type among groups $\mathrm{A}$, group $\mathrm{B}$, and group $\mathrm{C}$.

Association of grip and pinch strengths with K-MBI score in group A (Table 2)

Statistically significant positive correlations were observed among grip strength, three types of pinch strength, K-MBI total score, and all the subitems measured in the affected dominant hand of the right hemiplegic patient group. Particularly, a strong positive correlation ( $\mathrm{r}=0.716$, $\mathrm{p}<0.001)$ was observed between grip strength and dressing. Statistically significant positive correlations were also observed among grip strength of the unaffected nondominant hand of the right hemiplegic patient group, K-MBI total score, and all the subitems (K-MBI total score: $\mathrm{r}=0.510, \mathrm{p}<0.001$; hygiene: $\mathrm{r}=0.496, \mathrm{p}<0.001$; bathing: $r=0.485, p<0.001$; feeding: $r=0.327, p=0.02$; toileting: $\mathrm{r}=0.511, \mathrm{p}<0.001$; dressing: $\mathrm{r}=0.331, \mathrm{p}=0.01$ ). Of the three pinch strengths of the unaffected nondominant hand in the right hemiplegic patient group, lateral pinch strength showed significantly positive correlations with the K-MBI total score $(\mathrm{r}=0.318, \mathrm{p}=0.02)$, hygiene $(\mathrm{r}=0.291, \mathrm{p}=0.03)$, bathing $(\mathrm{r}=0.370, \mathrm{p}=0.005)$, and toileting $(\mathrm{r}=0.359$, $\mathrm{p}=0.007)$. Palmar pinch strength showed significant correlation with the K-MBI total score $(\mathrm{r}=0.363, \mathrm{p}=0.006)$, hygiene $(\mathrm{r}=0.345, \mathrm{p}=0.01)$, bathing $(\mathrm{r}=0.359, \mathrm{p}=0.007)$, and toileting $(\mathrm{r}=0.356, \mathrm{p}=0.008)$. Tip pinch strength also showed positive correlation with the K-MBI total score $(\mathrm{r}=0.285, \mathrm{p}=0.04)$ and toileting $(\mathrm{r}=0.282, \mathrm{p}=0.04)$.

The grip strength of the affected nondominant hand in the left hemiplegic patient group showed significantly positive correlations with the K-MBI total score $(\mathrm{r}=0.484, \mathrm{p}=0.002)$, hygiene $(\mathrm{r}=0.502, \mathrm{p}=0.001)$, bathing $(\mathrm{r}=0.593, \mathrm{p}<0.001)$, feeding $(\mathrm{r}=0.320, \mathrm{p}=0.04)$, and dressing $(\mathrm{r}=0.635, \mathrm{p}<0.001)$. The lateral pinch strength of the affected nondominant hand in the left hemiplegic patient group showed significantly positive correlations with the K-MBI total score $(\mathrm{r}=0.347, \mathrm{p}=0.03)$, hygiene ( $\mathrm{r}=0.401, \mathrm{p}=0.01)$, bathing $(\mathrm{r}=0.495, \mathrm{p}=0.001)$, and dressing $(r=0.468, p=0.002)$. Palmar pinch strength had significantly positive correlations with hygiene $(\mathrm{r}=0.472, \mathrm{p}=0.002)$, bathing $(\mathrm{r}=0.400, \mathrm{p}=0.01)$, and dress-

Table 2. Correlations between K-MBI and hand power of group A

\begin{tabular}{|c|c|c|c|c|c|c|c|c|}
\hline \multirow{2}{*}{ K-MBI } & \multicolumn{4}{|c|}{ HP (affected side) } & \multicolumn{4}{|c|}{ HP (unaffected side) } \\
\hline & GS & LP & PP & TP & GS & $\mathbf{L P}$ & PP & $\mathbf{T P}$ \\
\hline \multicolumn{9}{|c|}{ Right hemiplegia (n=55) } \\
\hline Hygiene & $0.646^{* * *}$ & $0.574^{* * *}$ & $0.439^{* *}$ & $0.532^{* * *}$ & $0.496^{* * *}$ & $0.291^{*}$ & $0.345^{*}$ & 0.240 \\
\hline Bathing & $0.632^{* * *}$ & $0.584^{* * *}$ & $0.436^{* *}$ & $0.504^{* * *}$ & $0.485^{* * *}$ & $0.370^{* *}$ & $0.359^{* *}$ & 0.243 \\
\hline Feeding & $0.514^{* * *}$ & $0.409^{* *}$ & $0.339^{*}$ & $0.404^{* *}$ & $0.327^{*}$ & 0.201 & 0.219 & 0.159 \\
\hline Toileting & $0.596^{* * *}$ & $0.606^{* * *}$ & $0.507^{* * *}$ & $0.568^{* * *}$ & $0.511^{* * *}$ & $0.359^{* *}$ & $0.356^{* *}$ & $0.282 *$ \\
\hline Dressing & $0.716^{* * *}$ & $0.614^{* * *}$ & $0.465^{* * *}$ & $0.542^{* * *}$ & $0.331^{*}$ & 0.111 & 0.155 & 0.000 \\
\hline Total & $0.569^{* * *}$ & $0.554^{* * *}$ & $0.416^{* *}$ & $0.487^{* * *}$ & $0.510^{* * *}$ & $0.318^{*}$ & $0.363^{* *}$ & $0.285^{*}$ \\
\hline \multicolumn{9}{|c|}{ Left hemiplegia $(n=40)$} \\
\hline Hygiene & $0.502^{* *}$ & $0.401^{*}$ & $0.472^{* *}$ & $0.570^{* * *}$ & 0.105 & -0.023 & 0.085 & 0.049 \\
\hline Bathing & $0.593^{* * *}$ & $0.495^{* *}$ & $0.400^{*}$ & $0.592^{* * *}$ & 0.031 & -0.015 & 0.063 & 0.055 \\
\hline Feeding & $0.320^{*}$ & 0.212 & 0.239 & 0.304 & 0.214 & .029 & 0.084 & 0.106 \\
\hline Toileting & 0.253 & 0.173 & 0.027 & 0.231 & 0.050 & 0.087 & 0.285 & 0.120 \\
\hline Dressing & $0.635^{* * *}$ & $0.468^{* *}$ & $0.391^{*}$ & $0.520^{* *}$ & 0.008 & -0.003 & 0.105 & 0.015 \\
\hline Total & $0.484^{* *}$ & $0.347^{*}$ & 0.190 & $0.401^{*}$ & 0.107 & 0.116 & 0.240 & 0.120 \\
\hline
\end{tabular}

Values are correlation coefficient.

K-MBI, Korean version of Modified Barthel Index; HP, hand power; GS, grip strength; LP, lateral pinch; PP, palmar pinch; TP, tip pinch.

${ }^{*} \mathrm{p}<0.05,{ }^{* *} \mathrm{p}<0.01,{ }^{* * *} \mathrm{p}<0.001$ 
ing $(r=0.391, p=0.01)$. The pinch strength had significant correlation with the K-MBI total score $(\mathrm{r}=0.401, \mathrm{p}=0.01)$, hygiene $(\mathrm{r}=0.570, \mathrm{p}<0.001)$, bathing $(\mathrm{r}=0.592, \mathrm{p}<0.001)$, and dressing $(\mathrm{r}=0.520, \mathrm{p}<0.001)$ items. However, the grip strength of the unaffected dominant hand in the left hemiplegic patient group or the three types of pinch strength did not show statistically significant ( $p>0.05)$ correlations with the K-MBI total score or its subitems.

In summary, in group $\mathrm{A}$, the grip strength and the three types of pinch strength of the affected dominant hand in the right hemiplegic patients showed statistically significant positive correlations with the K-MBI total score and all other subitems. The grip strength and three types of the pinch strength of unaffected nondominant hand of the right hemiplegic patients and the affected nondominant hand of the left hemiplegic patients showed statistically significant positive correlations with the KMBI total score and other subitems in overall. However, no statistically significant positive correlation was observed between the grip strength or the three types of pinch strength of the unaffected dominant hand in the left hemiplegic patients and the K-MBI total score or its subitems.
Association of grip and pinch strengths with K-MBI score in group B (Table 3)

The grip strength of the affected dominant hand in the right hemiplegic patient group showed statistically significant positive correlations with the K-MBI total score ( $\mathrm{r}=0.394, \mathrm{p}=0.009)$, bathing $(\mathrm{r}=0.309, \mathrm{p}=0.04)$, toileting $(\mathrm{r}=0.325, \mathrm{p}=0.03)$, and dressing $(\mathrm{r}=0.443, \mathrm{p}=0.003)$. Of the three types of pinch strength of the affected dominant hand in the right hemiplegic patient group, only the lateral pinch strength and dressing items showed statistically significant positive correlation $(r=0.325, p=0.03)$. The grip strength and the three types of pinch strength of the unaffected nondominant hand in the right hemiplegic patient group showed statistically significant positive correlation with bathing (grip strength: $\mathrm{r}=0.434$, $\mathrm{p}=0.004$; lateral pinch strength: $\mathrm{r}=0.324, \mathrm{p}=0.03$; palmar pinch strength: $r=0.326, p=0.03$; tip pinch strength: $r=0.334$, $\mathrm{p}=0.03)$.

The grip strength of the affected nondominant hand in the left hemiplegic patient group showed statistically significant positive correlations with the K-MBI total score $(\mathrm{r}=0.416, \mathrm{p}=0.04)$, toileting $(\mathrm{r}=0.556, \mathrm{p}=0.003)$, and dressing $(r=0.490, p=0.01)$. The three types of pinch strength of the affected nondominant hand in the hemiplegic patient

Table 3. Correlations between K-MBI and hand power of group B

\begin{tabular}{|c|c|c|c|c|c|c|c|c|}
\hline \multirow{2}{*}{ K-MBI } & \multicolumn{4}{|c|}{ HP (affected side) } & \multicolumn{4}{|c|}{ HP (unaffected side) } \\
\hline & GS & $\mathbf{L P}$ & PP & TP & GS & $\mathbf{L P}$ & PP & TP \\
\hline \multicolumn{9}{|c|}{ Right hemiplegia $(\mathrm{n}=43)$} \\
\hline Hygiene & 0.092 & 0.079 & -0.174 & -0.188 & 0.193 & 0.146 & 0.161 & 0.183 \\
\hline Bathing & $0.309^{*}$ & 0.262 & 0.028 & -0.086 & $0.434^{* *}$ & $0.324^{*}$ & $0.326^{*}$ & $0.334^{*}$ \\
\hline Feeding & 0.294 & 0.259 & 0.174 & 0.074 & 0.137 & 0.100 & 0.000 & 0.115 \\
\hline Toileting & $0.325^{*}$ & 0.225 & 0.086 & 0.102 & 0.145 & 0.110 & 0.069 & 0.092 \\
\hline Dressing & $0.443^{* *}$ & $0.325^{*}$ & 0.114 & 0.144 & 0.052 & 0.048 & 0.062 & 0.094 \\
\hline Total & $0.394^{* *}$ & 0.267 & 0.072 & 0.044 & 0.256 & 0.200 & 0.222 & 0.198 \\
\hline \multicolumn{9}{|c|}{ Left hemiplegia $(n=26)$} \\
\hline Hygiene & 0.241 & 0.178 & 0.176 & 0.185 & 0.215 & 0.106 & 0.265 & 0.074 \\
\hline Bathing & 0.316 & 0.254 & 0.286 & 0.271 & 0.298 & 0.079 & 0.206 & 0.155 \\
\hline Feeding & 0.389 & $0.402^{*}$ & $0.440^{*}$ & $0.473^{*}$ & 0.303 & 0.285 & $0.393^{*}$ & 0.327 \\
\hline Toileting & $0.556^{* *}$ & $0.506^{* *}$ & $0.533^{* *}$ & $0.528^{* *}$ & 0.295 & 0.136 & 0.184 & 0.209 \\
\hline Dressing & $0.490^{*}$ & $0.440^{*}$ & $0.424^{*}$ & $0.433^{*}$ & 0.235 & 0.057 & 0.044 & 0.091 \\
\hline Total & $0.416^{*}$ & $0.389 *$ & $0.414^{*}$ & $0.412^{*}$ & $0.404^{*}$ & 0.233 & 0.269 & 0.268 \\
\hline
\end{tabular}

Values are correlation coefficient.

K-MBI, Korean version of Modified Barthel Index; HP, hand power; GS, grip strength; LP, lateral pinch; PP, palmar pinch; TP, tip pinch.

${ }^{*} \mathrm{p}<0.05,{ }^{* *} \mathrm{p}<0.01,{ }^{* * *} \mathrm{p}<0.001$. 
group showed statistically significant positive correlations with the K-MBI total score (lateral pinch strength: $\mathrm{r}=0.389, \mathrm{p}<0.05$; palmar pinch strength: $\mathrm{r}=0.414, \mathrm{p}=0.04$; tip pinch strength: $\mathrm{r}=0.412, \mathrm{p}=0.04$ ), feeding (lateral pinch strength: $r=0.402, p=0.04$; palmar pinch strength: $\mathrm{r}=0.440, \mathrm{p}=0.03$; tip pinch strength: $\mathrm{r}=0.473, \mathrm{p}=0.02$ ), toileting (lateral pinch strength: $\mathrm{r}=0.506, \mathrm{p}=0.008$; palmar pinch strength: $\mathrm{r}=0.533, \mathrm{p}=0.005$; tip pinch strength: $\mathrm{r}=0.528, \mathrm{p}=0.006$ ), and dressing (lateral pinch strength: $\mathrm{r}=0.440, \mathrm{p}=0.02$; palmar pinch strength: $\mathrm{r}=0.424, \mathrm{p}=0.03$; tip pinch strength: $\mathrm{r}=0.433, \mathrm{p}=0.03$ ). The grip strength of the hemiplegic patient group's unaffected dominant hand showed statistically significant positive correlation with the K-MBI total score $(r=0.404, p=0.04)$. Of the three types of pinch strength, the palmar pinch strength and feeding showed statistically significant positive correlations $(\mathrm{r}=0.393, \mathrm{p}<0.05)$.

In summary, in group B, the grip strength and the three types of pinch strength of the affected dominant hand in the right hemiplegic patient group showed statistically significant positive correlations with part of the items. The grip strength and the three types of pinch strength of the left hemiplegic patient group's affected nondominant hand showed statistically significant positive correlations with all items except the hygiene and bathing items. The grip strength and the three types of the pinch strength of the left hemiplegic patient group's unaffected dominant hand showed statistically significant positive correlations with some of the items.

Association of grip and pinch strengths with the K-MBI score in group C (Table 4)

The grip strength of the right hemiplegic patient group's affected dominant hand showed a statistically significant positive correlation with dressing $(\mathrm{r}=0.406, \mathrm{p}=0.02)$. Of the three types of pinch strength, the lateral pinch strength showed statistically significant positive correlations with the K-MBI total score $(\mathrm{r}=0.527, \mathrm{p}=0.001)$, bathing $(\mathrm{r}=0.424, \mathrm{p}=0.01)$, toileting $(\mathrm{r}=0.373, \mathrm{p}=0.03)$, and dressing $(\mathrm{r}=0.552, \mathrm{p}=0.001)$. The palmar pinch strength had significantly positive correlation with the K-MBI total score $(\mathrm{r}=0.482, \mathrm{p}=0.003)$, bathing $(\mathrm{r}=0.387$, $\mathrm{p}=0.02)$, toileting $(\mathrm{r}=0.391, \mathrm{p}=0.02)$, and dressing $(\mathrm{r}=0.511$, $\mathrm{p}=0.002$ ). The tip pinch strength had positive correlation with the K-MBI total score $(\mathrm{r}=0.434, \mathrm{p}=0.009)$, bathing $(\mathrm{r}=0.362, \mathrm{p}=0.03)$, and dressing $(\mathrm{r}=0.492, \mathrm{p}=0.003)$. Of the three types of pinch strength, the lateral pinch strength $(r=0.340, p<0.05)$ and palmar pinch strength $(r=0.335$,

Table 4. Correlations between K-MBI and hand power of group C

\begin{tabular}{|c|c|c|c|c|c|c|c|c|}
\hline \multirow{2}{*}{ K-MBI } & \multicolumn{4}{|c|}{ HP (affected side) } & \multicolumn{4}{|c|}{ HP (unaffected side) } \\
\hline & GS & LP & $\mathbf{P P}$ & TP & GS & LP & PP & TP \\
\hline \multicolumn{9}{|c|}{ Right hemiplegia $(\mathrm{n}=35)$} \\
\hline Hygiene & 0.101 & 0.302 & 0.329 & 0.240 & -0.043 & 0.222 & 0.162 & 0.091 \\
\hline Bathing & 0.261 & $0.424^{*}$ & $0.387^{*}$ & $0.362^{*}$ & -0.100 & 0.070 & 0.098 & -0.035 \\
\hline Feeding & 0.170 & 0.302 & 0.280 & 0.260 & 0.046 & 0.283 & 0.297 & 0.171 \\
\hline Toileting & 0.183 & $0.373^{*}$ & $0.391^{*}$ & 0.292 & 0.032 & $0.340^{*}$ & $0.335^{*}$ & 0.303 \\
\hline Dressing & $0.406^{*}$ & $0.552^{* *}$ & $0.511^{* *}$ & $0.492^{* *}$ & -0.148 & 0.258 & 0.206 & 0.132 \\
\hline Total & 0.309 & $0.527^{* *}$ & $0.482^{* *}$ & $0.434^{* *}$ & -0.084 & 0.240 & 0.221 & 0.105 \\
\hline \multicolumn{9}{|c|}{ Left hemiplegia $(n=38)$} \\
\hline Hygiene & $0.375^{*}$ & $0.443^{* *}$ & 0.204 & $0.426^{* *}$ & 0.035 & 0.080 & 0.275 & 0.144 \\
\hline Bathing & 0.281 & $0.337^{*}$ & 0.113 & $0.331^{*}$ & 0.240 & 0.284 & $0.411^{*}$ & $0.331^{*}$ \\
\hline Feeding & $0.368^{*}$ & 0.216 & 0.147 & 0.235 & 0.305 & $0.328^{*}$ & 0.313 & 0.298 \\
\hline Toileting & 0.310 & 0.218 & 0.062 & 0.255 & 0.181 & 0.115 & 0.235 & 0.182 \\
\hline Dressing & $0.386^{*}$ & $0.345^{*}$ & 0.175 & $0.404^{*}$ & 0.095 & 0.014 & 0.120 & 0.073 \\
\hline Total & $0.458^{* *}$ & $0.400^{*}$ & 0.185 & $0.454^{* *}$ & 0.216 & 0.086 & 0.219 & 0.161 \\
\hline
\end{tabular}

Values are correlation coefficient.

K-MBI, Korean version of Modified Barthel Index; HP, hand power; GS, grip strength; LP, lateral pinch; PP, palmar pinch; TP, tip pinch.

${ }^{*} \mathrm{p}<0.05,{ }^{* *} \mathrm{p}<0.01,{ }^{* * *} \mathrm{p}<0.001$ 
$\mathrm{p}<0.05)$ of the right hemiplegic patient group's unaffected nondominant hand showed statistically significant positive correlation with toileting.

The grip strength of the left hemiplegic patient group's affected nondominant hand showed statistically significant positive correlations with the K-MBI total score $(\mathrm{r}=0.458, \mathrm{p}=0.004)$, hygiene $(\mathrm{r}=0.375, \mathrm{p}=0.02)$, feeding $(\mathrm{r}=0.368, \mathrm{p}=0.02)$, and dressing $(\mathrm{r}=0.386, \mathrm{p}=0.02)$. Of the three types of pinch strength, the lateral pinch strength showed statistically significant positive correlation with the K-MBI total score $(\mathrm{r}=0.400, \mathrm{p}=0.01)$, hygiene $(\mathrm{r}=0.443, \mathrm{p}=0.005)$, bathing $(\mathrm{r}=0.337, \mathrm{p}=0.04)$, and dressing $(\mathrm{r}=0.345, \mathrm{p}=0.03)$. The tip pinch strength had positive correlation with the K-MBI total score $(\mathrm{r}=0.454, \mathrm{p}=0.004)$, hygiene $(\mathrm{r}=0.426, \mathrm{p}=0.008)$, bathing $(\mathrm{r}=0.331, \mathrm{p}=0.04)$, and dressing $(r=0.404, p=0.01)$. Of the three types of pinch strength of the left hemiplegic patient group's unaffected dominant hand, the lateral pinch strength showed statistically significant positive correlation with feeding $(r=0.328, p=0.04)$. The palmar pinch strength and tip pinch strength had positive correlation with bathing (palmar pinch strength: $\mathrm{r}=0.411, \mathrm{p}=0.01$; tip pinch strength: $\mathrm{r}=0.331, \mathrm{p}<0.05)$.

In summary, in group $C$, the grip strength and the three types of the pinch strength of the right hemiplegic patient group's affected dominant hand showed statistically significant positive correlations with all items except hygiene and feeding. The grip strength and the three types of pinch strength of the right hemiplegic patient group's unaffected nondominant hand showed statistically significant positive correlations with some of the toileting items. The grip strength and the three types of pinch strength of the left hemiplegic patient group's affected nondominant hand showed statistically significant positive correlations with all items. The grip strength and the three types of pinch strength in the left hemiplegic patient group's unaffected dominant hand showed statistically significant positive correlations with some of the items.

\section{DISCUSSION}

According to this study, a significant correlation between the grip and pinch strengths and the K-MBI score was observed in both hands of the right hemiplegic patients at subacute stage and in the affected hand of the left hemiplegic patients. In addition, the grip and pinch strengths of the affected side showed more correlations with the K-MBI score with the progression from the subacute to late chronic stage than with other items.

Representative hypotheses of the neurophysiologic mechanism on the post-stroke recovery include 1) ipsilateral motor pathway that connects the unaffected cerebral hemisphere with the affected extremities, 2) peri-lesional reorganization, 3 ) the recovery of the lateral corticospinal tract, and 4) the contribution of the other motor areas. Of these hypotheses, studies on the ipsilateral motor pathway have been actively conducted [2]. The most well accepted activation mechanism of the ipsilateral motor pathway is 'disinhibition hypothesis.' In normal cases, both cerebral hemispheres maintain a balance of transcallosal inhibition through the corpus callosum. However, when stroke develops, the interhemispheric transcallosal inhibition from the affected hemisphere to the unaffected hemisphere decreases. Therefore, the unaffected hemisphere starts to function from the origin of the ipsilateral motor pathway. The following three ipsilateral motor pathways have been suggested: the uncrossed anterior corticospinal tract; the cortico-reticulospinal or cortico-vestibulospinal tract; and a new pathway. In a recent study, activities of the contralesional motor cortex were confirmed to be important for stroke patients within one month [19]. This period is critical for adjusting the contralesional motor cortical activities. However, this critical period has not been well known. Patients who recovered due to activation of the ipsilateral motor pathway from the contralesional motor cortex show less recovery than patients whose contralateral motor cortex is activated showing dominant mirror movements [19]. It is important to inhibit the ipsilateral motor cortical activities and promote contralateral motor cortical activities at that time. Intense complex works that require a long period or repetitive transcranial magnetic stimulations to promote ipsilateral motor cortical activities and repetitive transcranial magnetic stimulations or specific type of works have been reported to inhibit ipsilateral motor cortex.

Studies supporting 'bilateral training' [6] are based on the following mechanisms [1]. The first mechanism is corticospinal activation. The second mechanism is activation of the affected contralateral hemisphere. Stroke patients have increased activity level of the affected contralateral hemisphere. Their activity amplitude level is 
further increased when complex works are performed. Accordingly, the affected contralateral hemisphere is involved in the control of post-stroke movements. Another mechanism is normalization of the inhibiting mechanism in the 'disinhibition hypothesis'.

When patients whose corticospinal tract is preserved in response to motor evoked potential test, the unaffectedside upper extremities constraint-induced therapy is conducted. When patients do not respond to motor evoked potential test but their posterior limb of internal capsule is anatomically and symmetrically well preserved, a method to induce the cortical excitability of the affected hemisphere is used, followed by a unilateral therapy. In patients whose corticospinal tract is not fully preserved in brain MRI or transcranial magnetic stimulation, method to induce the overall cortical excitability must be used. Intense treatments (bilateral training with rhythmic auditory feedback or electrical stimulation) are suggested for the affected or contralateral hemisphere [20]. In this study, these suggestions could not be applied to subjects due to the lack of information on the locations of lesions or on the preservation of the anatomical structure. However, the subacute stage patient group showed differences according to the affected side, confirming that separate strategies are required in the rehabilitation treatments of subacute stage stroke patients according to the affected dominant hand.

Hand muscle strength and functions that are preserved in hemiplegic stroke patients is often called 'unaffected side' or unaffected. The strength and quickness of the 'unaffected side' hand is known to be slightly deteriorated. Accordingly, it may be better to express it as 'slightly affected side' or 'relatively unaffected side.' In a previous study on the correlation of the grip and pinch strengths with MBI through follow-up of a mean of 36.5 and 64.1 days after onset targeting the 'relatively unaffected side' hands of 20 right cerebral lesion patients who had dominant right hand and affected nondominant hand, the total score of the bathing item has been suggested to increase with recovery of the lateral pinch strength [21]. However, no correlation with bathing items was confirmed in this study. Instead, the grip and lateral pinch strengths of the right hemisphere lesion patient group's dominant hand and the dressing items showed consistently positive correlations in groups A, B, and C. In particular, group A showed a strong positive cor- relation. The grip strength of the left hemisphere lesion patient group's affected nondominant hand showed consistently positive correlations with the K-MBI total score and dressing items. The lateral pinch and tip pinch strengths also showed consistently positive correlations with the K-MBI total score and dressing items. The grip and pinch strengths of the unaffected hand did not show consistent correlations with the K-MBI score. The dressing items often showed correlations with the grip and pinch strengths. This may be due to the fact that dressing requires both hands, which is different from other activities that could be carried out with one hand.

Right hemisphere lesion patients with unilateral hemisphere lesion prefer to use the dominant hand or the right hand four times more than to use the nondominant hand or the left hand. Left hemisphere lesion patients prefer to use the nondominant hand or the left hand two times more than to use the dominant hand or the right hand. They clearly prefer to use both hands compared to right hemisphere lesion patients [7]. In a following study, both right- and left-hemisphere lesion patient groups showed enhanced instrumental activities of daily livings (IADLs) performances with the increase in using both hands. When ADL were performed with one hand, no difference in ADL performance was observed in right hemisphere lesion patients with unaffected right hand. However, left hemisphere lesion patients with affected dominant hand showed poor ADL performance [22]. In Group A, the right hemisphere lesion patients with affected dominant hand showed significant positive correlations with all items. Strong positive correlations were observed between grip strength and some of the dressing items. The grip and pinch strengths of the unaffected nondominant hand were correlated to K-MBI score overall. This is different from left hemisphere lesion patients whose grip and pinch strengths of the affected nondominant hand showed correlations with the K-MBI score in overall, but their grip and pinch strengths of the unaffected dominant hand did not show correlations with the K-MBI score at all. In summary, in the cases of affected dominant left hemisphere with the affected dominant hand, both hands are used for full-scale ADL. In particular, the preservation of the affected dominant hand muscle strength was associated with ADL performance. In the case of left hemiplegic patients with the right hemisphere lesion as nondominant hemisphere with affected non- 
dominant hand, post-stroke ADL was performed using the dominant hand that was used for pre-stroke ADL. Preservation of muscle strength of the affected nondominant hand and participation in ADL may determine the performance.

In a Korean retrospective study on changes in MBI score according to changes in hand functions measured through the Jebsen Hand Function Test targeting 31 dominant hemisphere lesion patients and 13 nondominant hemisphere lesion patients [23], both dominant and nondominant hemisphere lesion patient groups' unaffected hand functions showed significant correlations with the K-MBI score at the 7 th week of onset. At 6 th months, the dominant hemisphere lesion patient group showed a significant correlation in the affected side or the dominant hand. The nondominant hemisphere lesion patient group showed a significant correlation in the unaffected side or the dominant hand. Accordingly, the unaffected hand functions were important for ADL in early stage. However, eventually the dominant hand functions were confirmed to be important in that study. In this study, hand function assessment tools were not investigated. Therefore, direct comparison between the two studies is impossible. However, in subacute stage right hemiplegic patients, bilateral hand grip and pinch strengths of the affected hand were found to be associated with the K-MBI score. In subacute left hemiphlegic patients, affected hand grip and pinch strengths were found to be associated with the K-MBI score. In late chronic stage patients, K-MBI score was affected by the affected side grip and pinch strengths regardless of the affected dominant hand, which is different from results of previous studies.

In a previous study targeting chronic stage patients after stroke on measuring the damage and functional levels using arm strength, grip strength, pain, tone, and sensation to confirm the effects of the dominant hemisphere, grip strength mainly affected the damage level and functional recoveries [24]. The affected dominant hemisphere did not affect the functional levels measured through Chedoke Arm and Hand Activity Inventory, Motor Activity Log, and Reintegration to Normal Living Index in this study. However, this study targeted late chronic stage patients who were trained for ADL through compensatory method. Therefore, chronic stage patients would be affected. As shown in this study, the association between the grip and pinch strengths and the K-MBI score decreased with the progression of disease from chronic stage (rehabilitation was completed and ADL was possible) to late chronic stage. This result is in consistent with results of a previous study [24].

There are several limitations of this study. First, as a retrospective study, effective factors such as the type and intensity of occupational therapy and patient participation were not considered. We only measured grip and pinch strengths. Other than muscle strength, no data for assessing functions and stroke severity were obtained. In particular, cognitive and sensory factors that could affect ADL independence were not completely excluded [25]. Second, since patients could obtain 20 or more in the score of MMSE-K, a two-step command was used in this study. Patients with severer stroke could be excluded in the future. Third, the investigated grip and pinch strengths were not compared to data of the same-age healthy Korean population. In addition, we did not use assessment tool such as Edinburgh Handedness Inventory to determine the handedness, althouth such method is widely used for studies in stroke patients. Instead, occupational therapists reported the handedness of patients according to previous preference and present performance in daily tasks including writing, using chopsticks, and brushing. Because handedness could have influence on grip/pinch strength, more precise determination of dominance using Edinburgh Handedness Inventory is needed in future studies to compare right/left side in stroke patients.

In conclusion, for subacute stage stroke patients, ADL performance of the right hemiplegic patients was associated with the preserved muscle strength of the 'affected side' (affected dominant hand) and 'relatively unaffected side' (nondominant hand). In ADL performance, the role of the dominant hand was thought to be important after stroke. Left hemiplegic patients with affected nondominant hand have 'relatively unaffected side'. They could perform ADL well with the dominant hand whose muscle strength and functions were not severely deteriorated. The muscle strength of the 'affected side' (nondominant hand) could partly affect activities that require both hands. The correlation between the grip and pinch strengths and ADL performance decreased with stroke progressed to late chronic stage. ADL tended to be affected by the recovery in muscle strength of the 'affected side' regardless whether the dominant hand is affected. 


\section{CONFLICT OF INTEREST}

No potential conflict of interest relevant to this article was reported.

\section{REFERENCES}

1. Stoykov ME, Corcos DM. A review of bilateral training for upper extremity hemiparesis. Occup Ther Int 2009;16:190-203.

2. Jang SH. A review of the ipsilateral motor pathway as a recovery mechanism in patients with stroke. NeuroRehabilitation 2009;24:315-20.

3. Lang CE, Bland MD, Bailey RR, Schaefer SY, Birkenmeier RL. Assessment of upper extremity impairment, function, and activity after stroke: foundations for clinical decision making. J Hand Ther 2013;26:104-14.

4. Stevenson T, Thalman L, Christie H, Poluha W. Constraint-induced movement therapy compared to dose-matched interventions for upper-limb dysfunction in adult survivors of stroke: a systematic review with meta-analysis. Physiother Can 2012;64:397-413.

5. McIntyre A, Viana R, Janzen S, Mehta S, Pereira S, Teasell R. Systematic review and meta-analysis of constraint-induced movement therapy in the hemiparetic upper extremity more than six months post stroke. Top Stroke Rehabil 2012;19:499-513.

6. McCombe Waller S, Whitall J. Hand dominance and side of stroke affect rehabilitation in chronic stroke. Clin Rehabil 2005;19:544-51.

7. Rinehart JK, Singleton RD, Adair JC, Sadek JR, Haaland KY. Arm use after left or right hemiparesis is influenced by hand preference. Stroke 2009;40:545-50.

8. Sangha H, Lipson D, Foley N, Salter K, Bhogal S, Pohani $\mathrm{G}$, et al. A comparison of the Barthel Index and the Functional Independence Measure as outcome measures in stroke rehabilitation: patterns of disability scale usage in clinical trials. Int J Rehabil Res 2005;28:135-9.

9. Shah S, Vanclay F, Cooper B. Improving the sensitivity of the Barthel Index for stroke rehabilitation. J Clin Epidemiol 1989;42:703-9.

10. Jung HY, Park BK, Shin HS, Kang YK, Pyun SB, Paik NJ, et al. Development of the Korean version of Modified Barthel Index (K-MBI): multi-center study for subjects with stroke. J Korean Acad Rehabil Med 2007;31:283-
97.

11. Heller A, Wade DT, Wood VA, Sunderland A, Hewer RL, Ward E. Arm function after stroke: measurement and recovery over the first three months. J Neurol Neurosurg Psychiatry 1987;50:714-9.

12. Shin H, Moon SW, Kim GS, Park JD, Kim JH, Jung MJ, et al. Reliability of the pinch strength with digitalized pinch dynamometer. Ann Rehabil Med 2012;36:394-9.

13. Mathiowetz V, Weber K, Volland G, Kashman N. Reliability and validity of grip and pinch strength evaluations. J Hand Surg Am 1984;9:222-6.

14. Goodson A, McGregor AH, Douglas J, Taylor P. Direct, quantitative clinical assessment of hand function: usefulness and reproducibility. Man Ther 2007;12:14452.

15. Li KY, Lin KC, Wang TN, Wu CY, Huang YH, Ouyang P. Ability of three motor measures to predict functional outcomes reported by stroke patients after rehabilitation. NeuroRehabilitation 2012;30:267-75.

16. Woldag H, Gerhold LL, de Groot M, Wohlfart K, Wagner A, Hummelsheim H. Early prediction of functional outcome after stroke. Brain Inj 2006;20:1047-52.

17. Skilbeck CE, Wade DT, Hewer RL, Wood VA. Recovery after stroke. J Neurol Neurosurg Psychiatry 1983;46:5-8.

18. Puh U. Age-related and sex-related differences in hand and pinch grip strength in adults. Int J Rehabil Res 2010;33:4-11.

19. Takeda K, Gomi Y, Imai I, Shimoda N, Hiwatari M, Kato $\mathrm{H}$. Shift of motor activation areas during recovery from hemiparesis after cerebral infarction: a longitudinal study with near-infrared spectroscopy. Neurosci Res. 2007;59:136-44.

20. Stinear CM, Barber PA, Smale PR, Coxon JP, Fleming $\mathrm{MK}$, Byblow WD. Functional potential in chronic stroke patients depends on corticospinal tract integrity. Brain 2007;130(Pt 1):170-80.

21. Han TR, Yoon KJ, Jung SH. The chronological review of uninvolved hand function in stroke patients. J Korean Acad Rehabil Med 2004;28:13-9.

22. Haaland KY, Mutha PK, Rinehart JK, Daniels M, Cushnyr B, Adair JC. Relationship between arm usage and instrumental activities of daily living after unilateral stroke. Arch Phys Med Rehabil 2012;93:1957-62.

23. Kim KE, Han TR, Kim JH. Importance of lesion laterality in hand function rehabilitation in stroke patients. J Korean Acad Rehabil Med 2007;31:661-7. 
24. Harris JE, Eng JJ. Individuals with the dominant hand affected following stroke demonstrate less impairment than those with the nondominant hand affected. Neurorehabil Neural Repair 2006;20:380-9.

25. Choi HY, Park SM, Park SJ, Chung KH, Lee YT, Lee
PK, et al. Relationship between cognitive-perceptual function and functional independence in patients with ischemic stroke. J Korean Acad Rehabil Med 2007;31:630-5. 